Tomoki Nishiyama MD PhD, ${ }^{\star \dagger}$

Takashi Matsukawa MD PhD, $\ddagger$

Kazuo Hanaoka MD PhD, ${ }^{\dagger}$

Charles M. Conway PhD*

\title{
Interactions between nicardipine and enflurane, isoflurane, and sevoflurane
}

Purpose: During nicardipine induced hypotension, different inhalational anaesthetics may have different effects on haemodynamic variables, sympathetic function and drug metabolism. Therefore, the haemodynamic effects and pharmacokinetics of nicardipine were studied in the presence of the three inhalation anaesthetics enflurane, isoflurane and sevofurane.

Methods: Thirty patients scheduled for neurosurgery were randomly assigned to one of three anaesthetic techniques: enflurane, isofurane or sevoflurane. Nicardipine $\left(0.017 \mathrm{mg} \cdot \mathrm{kg}^{-1}\right)$ was administered during stable anzesthesia and the following measurements made for $30 \mathrm{~min}$ : blood pressure, heart rate, and plasma concentration of norepinephrine, epinephrine and nicardipine.

Results: With sevoflurane, plasma concentrations of nicardipine, five minutes after administration, $\left(39.8 \pm 3.5 \mathrm{ng}^{\mathrm{mt}} \mathrm{f}^{-1}\right.$, mean \pm SEM) were higher $(P<0.05)$ than in the other two groups $\left(28.3 \pm 2.9 \mathrm{ng}^{\prime} \mathrm{ml}^{-1}, 32.6 \pm 4.3 \mathrm{ng}^{\prime} \mathrm{ml}^{-1}\right.$, enflurane and isoflurane, respectively). With isoflurane, the approximated half-life of nicardipine ( $14 \pm 4 \mathrm{~min})$ was shorter and clearance $\left(2.1 \pm 0.31 \cdot \mathrm{min}^{-1}\right)$ more rapid. Peak heart rates were similar in all groups but elevated rates continued longer with isoflurane ( $>30 \mathrm{~min}$ ). Nicardipine-induced reduction in blood pressure was greater with sevofurane but low pressures persisted for longer with isoflurane. Plasma catecholamine concentrations increased with isoflurane and enflurane, but not with sevoflurane: considerably higher epinephrine concentrations were seen with isoflurane.

Conclusion: This sturdy showed that the action of nicardipine is modified by different inhalational anaesthetic agents. Nicardipine has a prolonged duration of action in the presence of isoflurane and produces greater initial hypotension with sevofurane.

Objectif : Pendant l'hypotension induite à la nicardipine, les anesthésiques peuvent avoir des effets différents sur les variables hémodynamiques, l'activité sympathique et le métabolisme pharmacologique. Les effets hémodynamiques et pharmacocinétiques de la nicardipine ont été recherchés en présence de trois agents d'inhalation, l'enflurane, l'isoflurane et le sévoflurane.

Méthodes : Trente patients programmés pour une intervention neurologique ont été assignés aléatoirement à un des trois anesthésiques : enflurane, isoflurane ou sévoflurane. De la nicardipine $\left(0,017 \mathrm{mg} \cdot \mathrm{kg}^{-1}\right)$ a été administrée une fois l'anesthésie stabilisée. Pendant $30 \mathrm{~min}$, on a ensuite enregistré les variables suivantes : la pression artérielle, la fréquence cardiaque et la concentration plasmatique de la norépinéphrine, de l'épinéphrine et de la nicardipine.

Résultats : Avec le sévoflurane, les concentrations plasmatiques de nicardipine augmentaient cing minutes après l'administration $\left(39,8 \pm 3,5 \mathrm{ng}^{\prime} \mathrm{ml}^{-1}\right.$. moyenne \pm ÉT) à un niveau plus élevé $(P<0,05)$ qu'avec les decux autres agents

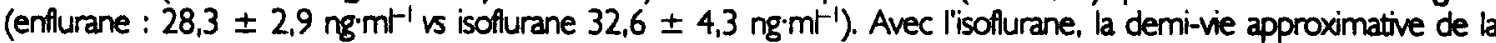
nicardipine ( $(14 \pm 4 \mathrm{~min})$ était plus courte et sa clarance plus rapide $\left(2,1 \pm 0,3 \mathrm{~L} \cdot \mathrm{min}^{-1}\right)$. Les frequences cardiaques maximales étaient identiques dans tous les groupes mais les fréquences élevées se sont maintenues plus longtemps avec l'isoflurane (<30 min). La baisse de la pression artérielle provoqué par la nicardipine était plus importante avec le sévoflurane mais les basses pressions ont persisté plus longtemps avec l'isoflurane. Les concentrations plasmatiques de catécholamines augmentaient avec lisoflurane et l'enflurane mais non avec le sévoflurane : on a observé des concentrations d'épinéphrine beaucoup plus elevees avec l'isoflurane.

Conclusion : Cette étude démontre que l'activité de la nicardipine est modifiée par divers agents inhalatoires. La nicardipine exerce une action prolongée en presence de l'isoflurane mais produit une hypotension initiale plus importante en présence du sévoflurane.

From the *Department of Anesthesiology, University of California, San Diego, USA, tDepartment of Anesthesiology, Faculty of Medicine, The University of Tokyo, Japan and 'Department of Anesthesia, Division of Operating Room, Yamanashi Medical University, Japan.

This study was carried out at the University of Tokyo, Japan.

Address correspondence to: Tomoki Nishiyama MD PhD, Department of Anesthesiology, University of California, San Dicgo,

9500 Gilman Drive, Mail Code 0818. La Jolla. CA 92093-0818. USA. Phone: 619-543-2297; Fax: 619-543-6070.

Accepted for publication July $1,1997$. 


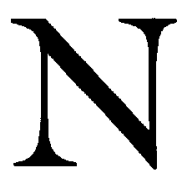

ICARDIPINE, a dihydropyridine calcium channel blocker, is often used for perioperative blood pressure control because it has an immediate action and a short lasting effect ${ }^{l}$ and causes only slight myocardial depression. ${ }^{2}$ The hypotension produced by nicardipine induces reflex sympathetic hypertonia. ${ }^{3}$ The inhalation anaesthetics have a vasodilating effect but different agents produce varying degrees of sympathetic activity. ${ }^{4}$ Therefore, nicardipine might affect sympathetic activity differently depending upon which general anaesthetic was used.

Nicardipine-induced hypotension results in decreased hepatic blood flow, ${ }^{5}$ but inhalational anaesthetics have differing effects on hepatic blood flow ${ }^{6}$ and on hepatocellular function. Therefore, metabolism of nicardipine by the liver during general anaesthesia might also differ depending upon the anaesthetic agent used. However, there are no studies comparing the effects of nicardipine in the presence of different general anaesthetics. The purpose of this study was to compare nicardipine pharmacokinetic behaviour and nicardipine-induced haemodynamic changes and sympathetic activity during general anaesthesia with three different inhalational agents: enflurane, isoflurane and sevoflurane.

In previous studies, nicardipine decreased blood pressure with ${ }^{7}$ or without ${ }^{1}$ producing increased heart rate. However, the latter study ${ }^{1}$ was done in conjunction with vascular surgery. In this setting, heart rate might be dependent, in part, on changes in stimulation associated with the surgical procedure, or influenced by the drugs administered prior to surgery. To avoid these possible confounding factors, we followed the methods of Fukusaki $e t a l^{7}$ and studied neurosurgical patients in whom blood pressure and heart rate are stable.

\section{Methods}

After institutional approval and informed consent, 30 patients (without liver or renal diseases; 40 to $70 \mathrm{yr}$ old, ASA class 1 or 2) scheduled for elective neurosurgery (cerebrovascular surgery and tumour resection with an anticipated duration of more than four hours) were studied. They were randomly divided, using the envelope method on the night before surgery, into three anaesthesia groups of 10 patients each, and assigned to receive either enflurane, isoflurane or sevoflurane.

As premedication, $0.01 \mathrm{mg} \cdot \mathrm{kg}^{-1}$ atropine and 1 $\mathrm{mg} \cdot \mathrm{kg}^{-1}$ hydroxyzine $i m$ were administered $30 \mathrm{~min}$ before the patients arrived at the operating room. Anaesthesia was induced with $2 \mathrm{mg} \cdot \mathrm{kg}^{-1}$ thiamylal, 0.1 $\mathrm{mg} \cdot \mathrm{kg}^{-1}$ midazolam, and $1 \mu \mathrm{g} \cdot \mathrm{kg}^{-1}$ fentanyl and tracheal intubation was facilitated with $0.15 \mathrm{mg} \cdot \mathrm{kg}^{-1}$ vecuronium. Anaesthesia was maintained with $31 \cdot \mathrm{min}^{-1}$ nitrous oxide in $21 \cdot \mathrm{min}^{-1}$ oxygen and fentanyl with enflurane, isoflurane, or sevoflurane 0.5 to $2.0 \%$ (end-tidal concentration measured with an Ultima ${ }^{\mathrm{TM}}$, Datex, Helsinki, Finland). Pancuronium was used as the muscle relaxant during surgery. End-tidal $\mathrm{CO}_{2}$ tension (measured by Ultima $^{\mathrm{TM}}$ ) was adjusted to $30-35 \mathrm{mmHg}$ by artificial ventilation. After induction of anaesthesia, a catheter was inserted into the radial artery to measure blood pressure and to collect blood samples.

When the microsurgical procedure had started and blood pressure kept constant ( $\pm 5 \%$ compared with pre anaesthesia level), $0.017 \mathrm{mg} \cdot \mathrm{kg}^{-1}$ nicardipine was administered as a bolus. This dose was selected to approximate the usual delivery of nicardipine $1 \mathrm{mg}$ to a $60 \mathrm{~kg}$ patient (the average body weight in Japan). Blood pressure, heart rate, and plasma concentrations of nicardipine, epinephrine and norepinephrine were measured before and at 1,3 (blood pressure and heart rate only), 5 10, 2030 $\mathrm{min}$ after nicardipine administration. Plasma epinephrine and norepinephrine concentrations were measured with high-performance liquid chromatography (HPLC, NT detector, Yokohama Hewlett-Packard, Yokohama, Japan: detection limit $0.01 \mathrm{ng} \cdot \mathrm{ml}^{-1}$, a coefficient of variation of $2.2 \%$ for epinephrine and $2.6 \%$ for norepinephrine). Plasma nicardipine concentration was measured with HPLC (UV detector SPD-2A, Shimadzu, Hamamatsu, Japan: detection limit $3 \mathrm{ng} \cdot \mathrm{ml}^{-1}$, a coefficient of variation of $2.0 \%$ ). The pharmacokinetics of nicardipine were approximated by the trapezoidal method. For at least 30 $\mathrm{min}$ before and after nicardipine administration, the concentrations of inhalational anaesthetics (target: $0.5 \mathrm{MAC}$, minimum alveolar concentration) and the rate of crystalloid infusion ( $\left.2 \mathrm{ml} \cdot \mathrm{kg}^{-1} \cdot \mathrm{hr}^{-1}\right)$ were kept constant and no other drugs such as pancuronium or fentanyl were administered.

Possible differences in the distribution of patients across the three anaesthesia groups were compared for sex and surgical procedure using the chi-square test and for other demographic data using Kruskal-Wallis tests. Blood pressure, heart rate, plasma nicardipine and plasma catecholamine concentrations were compared across anaesthesia groups with analysis of variance (ANOVA) followed by Fisher's protected least significant difference (PLSD). Intragroup differences were studied with repeated measures ANOVA followed by Fisher's PLSD. A $P$ value $<0.05$ was considered statistically significant.

\section{Results}

Demographic data and concentrations of inhalational anaesthetics at the time of nicardipine administration showed no differences among the three anaesthesia groups (Table I). Before nicardipine administration, there were no differences in blood pressure or heart 
TABLE I Demographic data for patients in each anaesthesia group

\begin{tabular}{|c|c|c|c|}
\hline & Enflurane & Sevoflurane & Isoflurane \\
\hline Age (yr) & $57 \pm 4$ & $58 \pm 3$ & $60 \pm 4$ \\
\hline $\operatorname{Sex}(M / F)$ & $7 / 3$ & $3 / 7$ & $5 / 5$ \\
\hline Body weight (kg) & $58.0 \pm 4.1$ & $57.8 \pm 2.9$ & $55.9 \pm 4.8$ \\
\hline $\begin{array}{l}\text { Surgery } \\
\text { (Vascular/Tumour) }\end{array}$ & $5 / 5$ & $3 / 7$ & $5 / 5$ \\
\hline $\begin{array}{l}\text { Duration of } \\
\text { anaesthesia (min) }\end{array}$ & $467 \pm 38$ & $503 \pm 72$ & $485 \pm 82$ \\
\hline MAC & $0.5 \pm 0.08$ & $0.5 \pm 0.06$ & $0.5 \pm 0.07$ \\
\hline $\begin{array}{l}\text { Time of nicardipine } \\
\text { administration }(\min )^{*}\end{array}$ & $120 \pm 9$ & $118 \pm 6$ & $117 \pm 7$ \\
\hline $\begin{array}{l}\text { Fentanyl }(\mu \mathrm{g}) \text { prior to } \\
\text { nicardipine }\end{array}$ & $285 \pm 26$ & $257 \pm 33$ & $273 \pm 41$ \\
\hline $\begin{array}{l}\text { Pancuronium (mg) prior } \\
\text { to nicardipine }\end{array}$ & $3 \pm 1$ & $4 \pm 1$ & $3 \pm 1$ \\
\hline
\end{tabular}

mean \pm SEM

"time from start of anaesthesia

rate among the three groups: systolic blood pressure; $142 \pm 9 \mathrm{mmHg}$ (mean $\pm \mathrm{SEM}$ ), $148 \pm 8 \mathrm{mmHg}$, and $145 \pm 7 \mathrm{mmHg}$, and heart rate; $70 \pm 3$ beats. $\mathrm{min}^{-1}$, $72 \pm 3$ beats $\cdot \mathrm{min}^{-1}, 68 \pm 4$ beats $\mathrm{min}^{-1}$, in enflurane, isoflurane, sevoflurane group, respectively.

Three minutes after nicardipine administration peak reductions in blood pressure were observed in all anaesthesia groups (Figure 1). The sevoflurane induced reductions in blood pressure were greater than those for isoflurane $(P=0.01$ for diastolic pressure) or enflurane $(P<0.01$ for diastolic pressure). With isoflurane, reductions in blood pressure persisted for $30 \mathrm{~min}$ after nicardipine administration, but for sevoflurane and enflurane such reductions were only observed for 20 and $10 \mathrm{~min}$, respectively. Peak increases in heart rate were observed at three minutes after nicardipine injection in all anaesthesia groups (Figure 1). With isoflurane, the elevations in heart rate continued for at least $30 \mathrm{~min}$, whereas shorter durations of increased heart rate were noted with sevoflurane (five minutes) and enflurane (three minutes).

A large increase in plasma epinephrine concentration was observed with isoflurane anaesthesia following nicardipine administration (Figure 2), which exceeded the increase seen with enflurane $(P<0.01$ compared with other two groups at $10 \mathrm{~min}$ ). Increases in plasma norepinephrine concentration were also observed for these two anaesthetics. In contrast, no changes in either plasma epinephrine or norepinephrine concentrations were observed with sevoflurane.

The plasma nicardipine concentration at five minutes after injection was higher with sevoflurane anaesthesia $\left(39.8 \pm 3.5 \mathrm{ng} \cdot \mathrm{ml}^{-1}\right)$ than in the other two

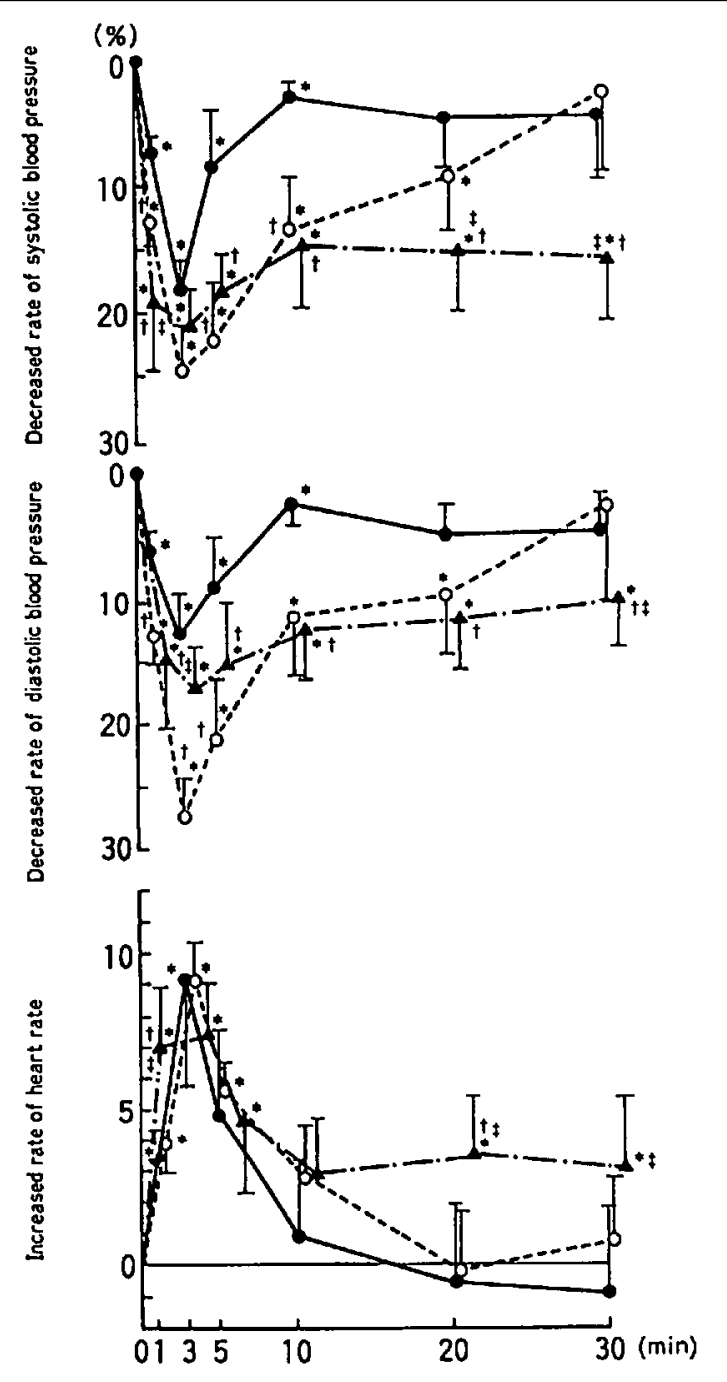

Time after the administration of nicardipine

FIGURE 1 Changes in blood pressure (top: systolic, middle: diastolic) and heart rate (bottom) following nicardipine administration $\left(0.017 \mathrm{mg} \cdot \mathrm{kg}^{-1}\right)$ as a function of time $(\mathrm{min})$ and the inhalational anaesthetic received (enflurane, isoflurane or sevoflurane). Values shown are the percent change from control values and represent the mean \pm SEM at each time point (control levels did not differ between the three groups, see text). Closed circles: enflurane anaesthesia, open circles: sevoflurane anaesthesia, closed triangles: isoflurane anaesthesia

${ }^{*} P<0.05$ vs control value

$\dagger P<0.05$ vs enflurane anaesthesia

$\mp P<0.05$ vs sevoflurane anaesthesia

groups $\left(28.3 \pm 2.9 \mathrm{ng} \cdot \mathrm{ml}^{-1}: P=0.03,32.6 \pm 4.3\right.$ ng. $\mathrm{ml}^{-1}: P=0.045$, enflurane and isoflurane, respectively) (Figure 3 ). The approximate elimination halflife $\left(t^{1 / 2}\right)$ of nicardipine was shorter and approximate nicardipine clearance was more rapid with isoflurane than for the other two anaesthetics (Table II). 


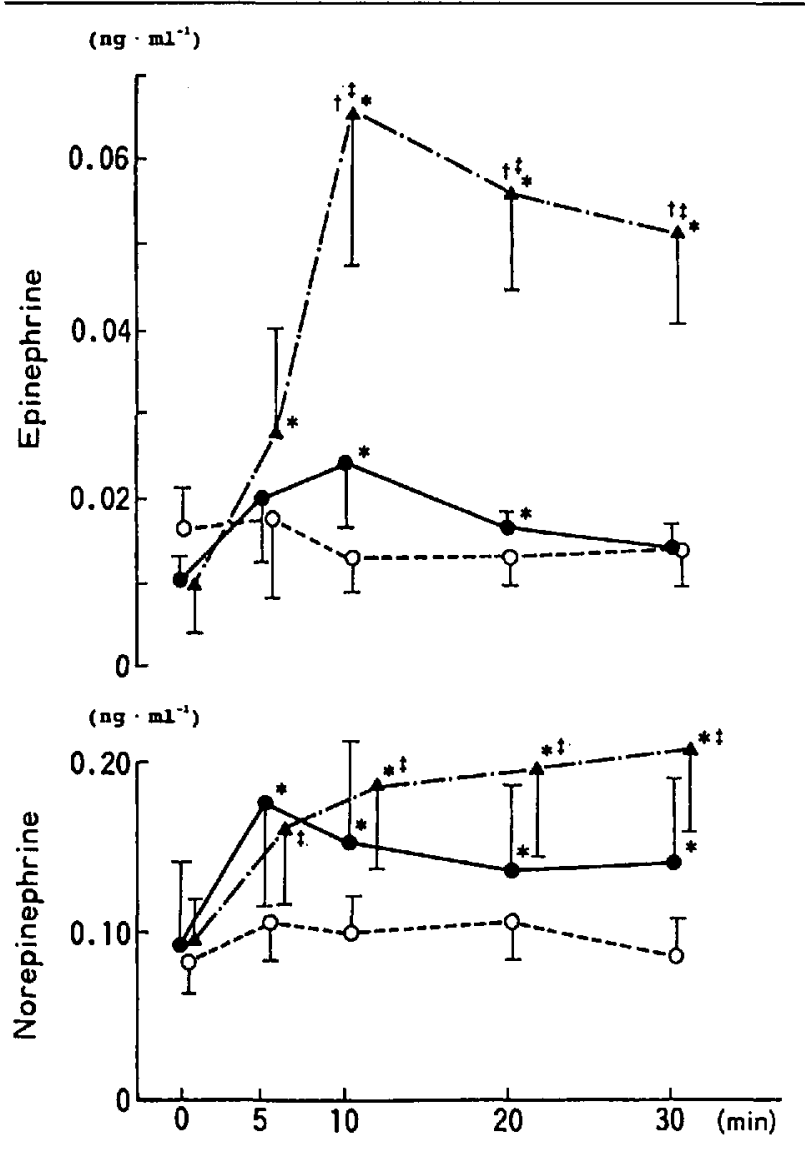

Time after the administration of nicardipine

FIGURE 2 Plasma catecholamine concentrations (top: epinephrine, bottom: norepinephrine) following nicardipine $\left(0.017 \mathrm{mg} \cdot \mathrm{kg}^{-1}\right)$ administration as a function of time $(\mathrm{min})$ and the inhalation anaesthetic received (enflurane, isoflurane or sevoflurane). Values represent the mean \pm SEM concentration (ng $\mathrm{ml}^{-1}$ ) of epinephrine and norepinephrine (note: $y$-axis scales differ). Closed circles: enflurane anaesthesia, open circles: sevoflurane anaesthesia, closed triangles: isoflurane anaesthesia.

${ }^{*} P<0.05$ vs control value

${ }^{\dagger} P<0.05$ vs enflurane anacsthesia

$\mp P<0.05$ vs sevoflurane anaesthesia

TABLE II Approximated pharmacokinetics of nicardipine for each anaesthetic agent

\begin{tabular}{llll}
\hline & Enflurane $^{ \pm}$ & Sevoflurane $^{\ddagger}$ & Isoflurane $^{\ddagger}$ \\
\hline $\mathrm{Tl} / 2(\mathrm{~min})^{*}$ & $28 \pm 6$ & $29 \pm 7$ & $14 \pm 4^{\$ 1}$ \\
AUC $\left(\mathrm{ng} \cdot \mathrm{min} \cdot \mathrm{ml}^{-1}\right)^{\dagger}$ & $885 \pm 58$ & $1080 \pm 95$ & $689 \pm 101^{\$ 1}$ \\
Clearance $\left(1 \cdot \mathrm{min}^{-1}\right)$ & $1.2 \pm 0.1$ & $1.0 \pm 0.1$ & $2.1 \pm 0.3 \$ 1$ \\
\hline
\end{tabular}

*T1/2: elimination half-life

tAUC: area under the curve of plasma nicardipine concentration $\ddagger_{\text {values are mean } \pm \text { SEM }}$

$\$ P<0.05 v s$ enflurane anaesthesia

IP $<0.05 p s$ sevoflurane anaesthesia

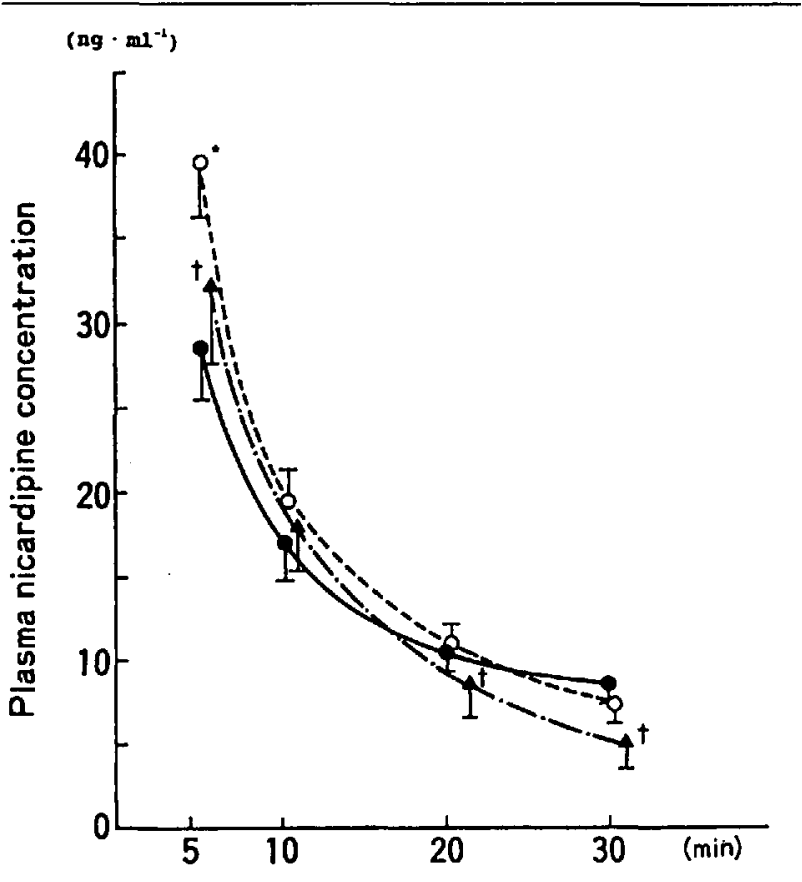

Time after the administration of nicardipine

FIGURE 3 Plasma nicardipine concentration (ng. $\mathrm{ml}^{-1}$, mean \pm SEM) following bolus nicardipine $\left(0.017 \mathrm{mg} \cdot \mathrm{kg}^{-1}\right)$ as a function of time ( $\mathrm{min}$ ) and anaesthesia received (enflurane, isoflurane or sevoflurane). Closed circles: enflurane anaesthesia, open circles: sevoflurane anaesthesia, closed triangles: isoflurane anaesthesia.

${ }^{*} P<0.05$ vs enflurane anaesthesia

$\dagger P<0.05$ ps sevoflurane anaesthesia

\section{Discussion}

The effects of nicardipine differed depending upon which inhalation anaesthetic was used. The main results of this study are: 1) nicardipine-induced decreases in blood pressure were greater with sevoflurane anaesthesia; 2) the duration of hypotension and tachycardia was longer, and plasma catecholamine concentrations were higher with isoflurane; 3) no changes in epinephrine or norepinephrine concentrations were detected with sevoflurane; and 4) nicardipine clearance was largest with isoflurane.

There have been no previous comparative studies of the interaction between nicardipine and inhalational anaesthetics. The present results suggest that the peak effect of nicardipine on blood pressure differs depending upon the anaesthetic agent, and was greater with sevoflurane than with enflurane and isoflurane. Interestingly, the decrease in blood pressure with sevoflurane was not accompanied by increased catecholamine levels as were seen in the other two anaesthesia groups. The reason for 
this discrepancy is unknown. However, inhalational anaesthetics can decrease sympathetic nerve activity by different degrees. ${ }^{8-10}$ It is possible that sevoflurane alone may have suppressed the reflex sympathetic hypertonia that usually follows nicardipine-induced decrease in blood pressure. Alternatively, short-lived increases in catecholamine concentrations may have been present between the first two plasma catecholamine measurements (0 and $5 \mathrm{~min}$ ) (Figure 2) and hence were not observed using our measurement methods. However, there were no differences in peak heart rate during this period (Figure 1, bottom) among the three anaesthesia groups and the data suggest that transient increases in catecholamine levels, if present, did not differ among groups.

In contrast to sevoflurane, increases in catecholamines were observed for isoflurane and enflurane (Figure 2). Even though inhalational anaesthetics suppress sympathetic activity under non-stimulated conditions, ${ }^{8-10}$ the addition of surgical stimulation ${ }^{11}$ or drug-induced hypotension ${ }^{7,12}$ to general anaesthesia can produce increased sympathetic activity. The increases in catecholamine concentrations seen during isoflurane or enflurane anaesthesia likely derive from nicardipineinduced hypotension. The difference in catecholamine changes between sevoflurane and the other two anaesthetics might be due to unique interactions between nicardipine and the specific inhalation anaesthetics. However, further studies are required to uncover the precise mechanism(s) that account for the different actions of nicardipine with these three anaesthetics.

With isoflurane anaesthesia, the duration of blood pressure decrease was longest (Figure 1), but the clearance of nicardipine was largest (Table II). This discrepancy requires further study to determine whether nicardipine exhibits enhanced binding to target receptors with isoflurane or some other mechanisms may be involved. The extended duration of increased heart rate in the isoflurane group (Figure 1) may result from intensified sympathetic adrenomedullary activity. This assertion is consistent with the long-lasting increase observed in plasma catecholamine concentrations (Figure 2).

Plasma nicardipine concentrations were measured only for $30 \mathrm{~min}$ after administration because of the difficulties in keeping the anaesthetic level and surgical stimulation constant for more than $60 \mathrm{~min}$ (including $30 \mathrm{~min}$ before nicardipine administration). Usually, estimation of pharmacokinetic variables using 2- or 3-compartment models requires sampling at least five times for two to three times the half-life. However, pharmacokinetic behaviour can be approximated using a trapezoidal method with four sampling points in shorter times. The half-lives of nicardipine with sevoflurane and enflurane anaesthesia (Table II) are consistent with the 22-45 min range reported previously. ${ }^{13}$ Nicardipine clearance was also similar for these two agents (Table II). In contrast, nicardipine clearance with isoflurane was estimated to be about twice as fast as that with enflurane or sevoflurane. Anaesthesia-induced differences in hepatic blood flow and/or in liver metabolic function may contribute to the more rapid metabolism of nicardipine seen with isoflurane. Previous studies ${ }^{14-15}$ have reported an increase in hepatic blood flow with isoflurane, with constant and decreased flow with sevoflurane and enflurane, respectively. In respect to sevoflurane anaesthesia, the reduction in blood pressure induced by nicardipine may have reduced hepatic flow and resulted in slower initial metabolism of nicardipine. That possibility is consistent with the high plasma levels of nicardipine seen at $5 \mathrm{~min}$ with sevoflurane (Figure 3 ). There are no reports about the differences in liver metabolic function between different inhalation anaesthetics. Therefore, the contribution of this factor should be studied further. In addition, longer sampling time could confirm these differences in pharmacokinetics.

In this study, the haemodynamic effects and pharmacokinetics of nicardipine were studied with three inhalational anaesthetics: enflurane, isoflurane and sevoflurane. The decrease in blood pressure was greatest with sevoflurane anaesthesia. Hypotension lasted longest and reflex sympathetic hypertonia was greatest with isoflurane anaesthesia. However, the clearance of nicardipine was the largest with isoflurane anaesthesia. The differences observed were not large and the number of data was small to determine their clinical importance. However, they suggest that when nicardipine is administered as a hypotensive agent during general anaesthesia, attention should be paid to the longer duration of hypotension with isoflurane and a greater peak effect with sevoflurane anaesthesia.

\section{References}

1 Kishi $\Upsilon$, Okumura F, Furuya H. Haemodynamic effects of nicardipine hydrochloride. Studies during its use to control acute hypertension in anaesthetized patients. Br J Anaesth 1984; 56: 1003-7.

2 Bongrani S, Razzetti $R$, Schiantarelli P. Cardiovascular effects of nicardipine in anesthetized open-chest dogs in the absence and presence of $B$-adrenergic receptor blockade: a comparison with nifedipine and verapamil. J Cardiovasc Pharmacol 1985; 7: 899-905.

3 Takeda S, Inada $\Upsilon$, Tashiro $N$, et al. Endocrine effects of hypotension induced by nicardipine in rabbits. (Japanese) Masui 1990; 39: 971-7. 
4 Bemard J-M, Pinaud M, Maquin-Mavier I, Remi J-P, Passuti N. Hypotensive anesthesia with isoflurane and enflurane during total hip replacement: a comparative study of catecholamine and renin angiotensin responses. Anesth Analg 1989; 69: 467-72.

5 Kito K, Arai T, Mori K, Morikawa S, Inubushi T. Hepatic blood flow and energy metabolism during hypotension induced by prostaglandin $\mathrm{El}$ and nicardipine in rabbits: An in vivo magnetic resonance spectroscopic study. Anesth Analg 1993; 77: 606-12.

6 Frink EJ Jr, Morgan SE, Coetzee A, Couzen PF, Brown $B R J r$. The effects of sevoflurane, halothane, enflurane, and isoflurane on hepatic blood flow and oxygenation in chronically instrumented greyhound dogs.

Anesthesiology 1992; 76: 85-90.

7 Fukusaki M, Miyako M, Fukui S, Haseba S, Gotob $\Upsilon$. Hemodynamics during induced hypotension with continuous administration of nicardipinc. (Japanese) Masui 1986; 35: 551-6.

8 Skovsted P, Sapthavichaikul S. The effects of isoflurane on arterial pressure, pulse rate, autonomic nervous activity, and barostatic reflexes. Can Anaesth Soc J 1977; 24: 304-14.

9 Nagayama T, Meguro K, Kurosawa M, Sato A. Effects of different concentrations of an inhaled anesthetic agent, sevoflurane on sympatho-adrenal medullary functions in rats. (Japanese) Masui 1993; 42: 1754-62.

L0 Saeki $\Upsilon$, Hasegawa $\Upsilon$, Shibamoto $T$, et al. The effects of sevoflurane, enflurane, and isoflurane on baroreceptorsympathetic reflex in rabbits. Anesth Analg 1996; 82: 342-8.

I1 Murakawa $T$, Satob $\Upsilon$, Kudo $T$, Kudo M, Matsuki $A$, Oyama $T$. Effects of sevoflurane anesthesia and surgery on plasma catecholamine levels. (Japanese) Masui 1989; 38: 1456-62.

12 Ray DC, Drummond GB. Haemodynamic responses to nicardipine in humans anaesthetized with halothane. Anaesthesia 1989; 44: 382-5.

L3 Ebata $T$, Okazaki $H$, Sha $M$, et al. The hypotensive effect and plasma concentration of nicardipine during general anesthesia. (Japanese) Jpn J Clin Ancsth 1985; 9: 1071-5.

14 Seyde WC, Longnecker DE. Anesthetic influences on regional hemodynamics in normal and hemorrhaged rats. Ancsthesiology 1984; 61: 686-98.

15 Conzen PF, Vollmar B, Habazettl H, Frink EJ, Peter $K$, Messmer $K$. Systemic and regional hemodynamics of isoflurane and sevoflurane in rats. Anesth Analg 1992; 74: $79-88$. 